\title{
La historia literaria colombiana a través de la teoría de los campos
}

PAULA ANDREA MARÍN COLORADO (2016). Novela, autonomía literaria y profesionalización del escritor en Colombia (1926-1970). Medellín: La Carreta

Este libro es el resultado de la tesis doctoral de Paula Marín, docente e investigadora del Instituto Caro y Cuervo (Bogotá). En él, la autora pretende mostrar «cómo se presenta la afirmación de la autonomía literaria en Colombia entre 1926 y 1970, y cuáles son sus característica particulares» (Marín, 2016:13). El enfoque teórico empleado es el de la teoría de los campos de producción cultural, tal como ha sido elaborada por Pierre Bourdieu. Este enfoque, hoy dominante en los estudios sociales de la literatura, postula que un «campo» es un espacio relativamente autónomo de relaciones específicas dentro del espacio social. En cada campo (literario, económico, político, etc.), una variedad de actores e instituciones ocupan diferentes posiciones de poder y luchan por apropiarse de sus formas específicas de capital. La lucha consiste también en apropiarse del poder de definición de los límites del campo y de sus formas legítimas de capital. Cada campo posee, entonces, sus intereses específicos, no equiparables a intereses económicos.

Según Bourdieu, un «campo literario» es un espacio social de relaciones donde se produce aquello que una sociedad define como literatura. En ese espacio participan los escritores, pero también las casas editoriales, las revistas de crítica, las instituciones públicas y privadas de apoyo a la creación, los grupos literarios y los lectores. La forma de capital específico que está en juego es el prestigio literario. Los actores y las instituciones luchan no solo por apropiarse de ese prestigio (capital simbólico), sino por definir su naturaleza. En su libro Las reglas del arte. Génesisy estructura del campo literario, publicado originalmente en 1992, Bourdieu estudia la formación del campo literario 
en Francia en el siglo XIX, desde su génesis hasta el momento de la «conquista de su autonomía», aquel en el cual se separa en tal grado de otros campos, como el político o el económico, que es posible reconocer en adelante la afirmación y el dominio simbólico de aquellas posiciones e instituciones que defienden y consagran el «arte por el arte» (o «intención estética pura», según una expresión empleada por Marín).

Para estudiar la evolución del campo literario en Colombia entre 1926 y 1970 -como se nota de inmediato, una «empresa» de clara inspiración bourdieuana- Marín acude a la figura de seis novelistas colombianos a los que agrupa en díadas; cada una de estas sería representativa de un determinado momento en la evolución del campo literario. Aunque incluye diferentes fuentes en su trabajo (entrevistas, artículos de prensa, crítica literaria, etc.), la fuente principal elegida por la autora para estudiar el punto de vista de cada escritor -sus «tomas de posición»-son las novelas mismas, de las cuales selecciona una en cada caso.

En primer lugar, la autora sitúa la díada compuesta por José Restrepo Jaramillo y Eduardo Zalamea Borda, representantes de un supuesto desafío a la «estética neoclásica», desafío que se habría expresado en sus novelas La novela de los tres (Restrepo Jaramillo, 1926) y 4 años a bordo de mí mismo (Zalamea Borda, 1934). Este momento inaugural habría dado paso, en la década de 1940, a un nuevo periodo de ataque directo, aunque limitado, al «campo del poder literario y político». Los representantes de esta postura serían Jaime Ardila Casamitjana, con su novela Babel (1943), y Jorge Zalamea, con El gran Burundún Burundá ha muerto (1952). Por último, Marín sitúa el periodo de conquista de la «autonomía institucional, intelectual y estética» del «campo literario colombiano» en la década de 1960. Gabriel García Márquez y La mala hora (1962), y Albalucía Ángel y Los girasoles en invierno (1970) serían representativos de este momento.

Basándose en Las reglas del arte, Marín establece tres componentes de la «autonomía literaria»: institucional, ideológica y estética. La primera alude a la posibilidad de los escritores de «vivir de la pluma», una posibilidad que solo se realiza con la extensión del público lector y el mercado editorial. En cuanto a la «autonomía ideológica», esta tiene que ver, según la autora, con la formación de un «pensamiento independiente», es decir, un pensamiento ajeno a los «partidos tradicionales» (Liberal y Conservador). Finalmente, la «autonomía estética» alude a la afirmación, por parte de los novelistas, de una «estética pura», reconocible en sus obras cuando «lo ético y lo estético no son aspectos excluyentes» (Marín, 2016: 11). El libro incluye, además, unas páginas dedicadas a «la teoría de los campos de producción simbólica vista desde América Latina», donde la autora presenta observaciones críticas sobre el uso de la noción de campo a este lado del mundo. Aquí se mencionan autores como Pascale Casanova, que en su libro La república mundial de las letras (publicado originalmente en francés en 1999) llama la atención hacia la dependencia y posición periférica de la literatura latinoamericana respecto a los modelos europeos; también a otros como Beatriz Sarlo y Carlos Altami- 
rano, quienes ya en los años 80 habían expresado reservas sobre el uso de la teoría de los campos a este lado del Atlántico: de un lado, no era posible esperar que en América Latina el campo literario tuviera «la regularidad y coherencia»-la homogeneidad-que Bourdieu le atribuía; de otro lado, y precisamente por esto, el uso de «dicotomías absolutas» como autónomo/heterónomo, dominado/dominante, subcampo de producción restringida/subcampo de gran producción era cuando menos problemático.

Así pues, pertrechada con la teoría de los campos, y atenta especialmente a las observaciones críticas de Sarlo y Altamirano, Marín emprende su investigación. Sin duda, Novela, autonomía literaria y profesionalización del escritor en Colombia (1926-1970) es un libro novedoso en el terreno de la historia y los estudios literarios en Colombia; su aporte a la comprensión de los vínculos entre la creación y recepción de la literatura y los procesos políticos y económicos de la primera mitad del siglo XX es significativo. Es destacable, además, el uso de múltiples fuentes documentales para estudiar las «tomas de posición» de los novelistas, y, sobre todo, el esfuerzo de la autora por hacer de las novelas mismas «superficies» donde se revelan los cambios sociales. Como se sabe, los investigadores literarios y los de las ciencias sociales se reprochan a menudo unos a otros la falta de «contexto» o la falta de «texto» en sus investigaciones. Mientras los primeros son acusados, a veces con razón, de convertir la obra literaria en una especie de fetiche autorreferencial, a los segundos se les reclama-también con razón-su escasa sensibilidad y atención hacia los aspectos íntimos del texto. En este sentido, el libro de Marín es un libro arriesgado: busca superar la oposición entre análisis interno y análisis externo de las obras literarias. Veamos su contenido con más detalle.

Primer momento (1926-1934): búsqueda de ruptura entre el «campo literario»y los «campos político y religioso». Dos novelistas: José Restrepo Jaramillo y Eduardo Zalamea Borda. Marín muestra cómo estos dos escritores, pese a sus vínculos con los partidos políticos y el empleo público, cuestionaron en sus declaraciones y en sus novelas el predominio de una concepción «estética neoclásica», una expresión que la autora nunca aclara del todo, y que reemplaza a veces por «arte humanista clásico», «estética regionalista-costumbrista» o «estética romántico-sentimental», la cual es reconocida y legitimada por los «agentes dominantes del campo», aunque tampoco nos revele quiénes son tales «agentes», más allá de la mención ritual de otras nociones abstractas como «élite letrada», la «Academia», las «autoridades literarias bogotanas», los «círculos letrados bogotanos» o el «oficialismo literario», quienes, al parecer, se oponen férreamente a cualquier cambio. Sabemos, sí, que esa «estética» casi incorpórea a la que se oponen los escritores seleccionados por Marín, y que parece cruzar el siglo $\mathrm{XX}$ colombiano como un fantasma, es una «estética» que privilegia el «fondo» sobre la «forma», así como las funciones pedagógicas, morales y nacionalistas en el arte.

Según Marín, la novedad de La novela de los tres (1926) en la literatura colombiana es su «carácter autorreflexivo»: una novela, según ella, «cada vez más autoconsciente, que 
cuestiona las convenciones literarias y defiende su autonomía señalándose a sí misma como un artificio, como una creación "libre" de un autor» (Marín, 2016: 54). En lo que se refiere a 4 años a bordo de mí mismo (1934), Marín considera que esta novela es importante para la afirmación de la «autonomía estética» porque «la historia que se narra es menos importante que la forma como se narra, esto es, a través de la traducción de la experiencia íntima del personaje» (Marín, 2016: 56). Aunque reconoce los avances en la búsqueda de la «autonomía literaria» que representaron escritores como Restrepo Jaramillo y Zalamea Borda, sobre todo en el plano estético, Marín señala también sus límites, por ejemplo su dependencia ideológica de los partidos políticos y su dependencia material del empleo público. Pero estos límites son, también, estéticos: el narrador de 4 años a bordo de mí mismo se reconcilia con la «ciudad fría y distante» donde nació, es decir, con «la modernización que se estaba llevando a cabo en la capital» (¿no privilegia Marín, con esta interpretación, el «fondo» sobre la «forma»?), y Restrepo Jaramillo habría carecido de los «elementos estables» (ं?) para escribir una novela que estuviera libre de todas las características de la novela tradicional.

Segundo momento (1943-1952): es el momento en que, según Marín, se consolida la ruptura (¿o el deseo de ruptura?) entre el campo literario y los campos político y religioso, pues surgen «tomas de posición abiertamente críticas» al respecto (Marín, 2016: 32). Aquí los precursores son Jaime Ardila Casamitjana y su novela Babel (1943), y Jorge Zalamea y El gran Burundún Burundá ha muerto (1952). Estos escritores representan un avance en el proceso de afirmación de la «autonomía literaria». De Ardila Casamitjana, el único de los escritores seleccionados que no desempeñó un cargo público, Marín destaca sus ideas «renovadoras», como el rechazo de la oposición entre forma y fondo en los textos literarios, pero así mismo su conciencia de la imposibilidad de ser un escritor «moderno» en su tiempo: no sólo porque «el campo del poder literario» se oponía a ello, sino porque el «poco público lector (...) tendía a seguir los direccionamientos establecidos por este sector de la intelectualidad» (Marín, 2016: 96). Para solucionar esta contradicción, Ardila habría acudido a una «estética modernista finisecular», la cual le habría permitido ser fiel a dos imperativos: «conseguir la consagración de parte de los agentes dominantes del campo intelectual y resguardar su autonomía intelectual y estética, aunque solo fuera en mínimo grado» (Marín, 2016: 96). En cuanto a Jorge Zalamea, Marín afirma, quizá apresuradamente, que «El gran Burundún Burundá ha muerto constituye una afirmación de la independencia ideológica y artística del escritor, y señala un momento del campo intelectual en el que ya es clara la diferenciación entre campo literario y campo político» (Marín, 2016: 96). De los casos analizados por la autora, considero que este y el de García Márquez son los mayores aciertos. Como se sabe, El gran Burundún es una obra en la que se mezclan géneros literarios, así como una sátira política de la figura de Laureano Gómez. Marín resalta, con buen juicio, la independencia ideológica que supuso esta obra en un contexto político como el del go- 
bierno de Gómez, así como su calidad (y novedad) estética y literaria. Pero afirmar que Zalamea y su novela coinciden con un momento de «clara diferenciación entre campo literario y campo político» es insostenible, no solo si se estudian otras figuras literarias e intelectuales de la época, sino si se ahonda en la trayectoria del propio Zalamea, tan estrechamente vinculada al Partido Liberal y al servicio público.

Tercer momento (1962-1970): Marín lo describe como la «época de la "novela de la violencia", el "Frente Nacional” y el denominado Grupo de Barranquilla» (Marín, 2016: 33). Según la autora, este momento

\section{[...] marca la emergencia de un mercado editorial más consolidado (...), una mejoría en las condiciones de profesionalización del escritor y la concretización de una crítica literaria con un lenguaje especializado que se apartó de los postulados de la estética humanista clásica. (Marín, 2016:32).}

Solo aquí sería posible hablar de un campo literario «en términos institucionales». Los novelistas seleccionados son Gabriel García Márquez y Albalucía Ángel. Ellos habrían conquistado la autonomía institucional («vivir de la pluma», sobre todo García Márquez), intelectual (un pensamiento independiente, no partidista) y estética (la afirmación del «arte por el arte»). En el caso de García Márquez es fundamental, como bien señala Marín, el deseo de ganar un público lector amplio sin rebajar la calidad literaria. A lo largo de las páginas dedicadas a este escritor, la autora muestra cómo su figura, sus «tomas de posición», su oficio y su pensamiento marcan efectivamente una ruptura en la vida intelectual y literaria colombiana. Para ilustrar lo anterior, Marín selecciona la novela La mala hora, ganadora del premio Esso en 1961 y publicada en Madrid un año después. El padre Félix Restrepo, director de la Academia de la Lengua y jurado del premio, había pedido a García Márquez eliminar las palabras "masturbándose" y "preservativo" antes de su publicación, así como cambiar el título original: Este pueblo de mierda. El escritor hizo lo último y eliminó la palabra «masturbándose». Cuando la novela fue publicada en Madrid, García Márquez se dio cuenta de que un corrector de pruebas había decidido «cambiar ciertos términos y almidonar el estilo en nombre de la pureza del lenguaje» (García Márquez citado en Marín, 2016: 170), un hecho que le molestó profundamente e hizo que desautorizara esta edición (dos años más tarde García Márquez aprobaría la edición de Era como la primera). Según Marín, la actuación de García Márquez -no solo la desaprobación de la edición española, sino la negativa a eliminar una de las palabras «obscenas»- fue una «desautorización» a la Academia; además, por medio de La mala hora el escritor pretendía develar la «falsa moral» imperante en su medio.

En cuanto a Albalucía Ángel, Marín la presenta como el culmen del proceso de autonomía estética e ideológica del campo literario. Para probar su afirmación, Marín 
acude a testimonios en los que la escritora pereirana defiende una literatura intimista (Los girasoles en invierno sería una concreción de este credo estético), ve la «función pública» del intelectual con desdén y rechaza incluso la pretensión de «vivir de la literatura», como cuando dice que su «vida no se ha basado en tener plata para escribir ni ganar plata con la escritura», y reivindica su posición marginal asegurando que no es «una escritora legible» porque pone «a la gente a pensar» (Ángel citada por Marín, 2016: 195). El libro de Paula Marín se cierra con una reflexión acerca de Arturo Suárez (18871956), novelista muy popular en la primera mitad del siglo XX (quizá el más editado y leído de todos), aunque en general despreciado por sus contemporáneos por el carácter «comercial» de su obra. Marín ve en Suárez a un escritor que buscó la profesionalización del oficio y cautivar a un público lector que era considerado «frívolo»: las mujeres; y muestra cómo las novelas sentimentales de Suárez recrearon figuras femeninas que cuestionaban, así fuera de manera contradictoria, su posición subordinada.

Como he planteado ya, considero que Novela, autonomía literariay profesionalización del escritor en Colombia (1926-1970) es un aporte significativo a los estudios sociales de la literatura colombiana. Es posible, sin embargo, que la promesa del libro: superar la oposición entre análisis interno y externo de las obras -una promesa arriesgada y difícil- se haya cumplido solo parcialmente: en efecto, resultan a veces un poco caprichosas las interpretaciones de Marín sobre las novelas seleccionadas, quedando a veces la sensación de que la autora «hace decir» a las obras lo que conviene a sus hipótesis. El otro gran problema del libro, a mi modo de ver, tiene que ver precisamente con sus hipótesis y su método: ¿no es acaso excesivo hacer afirmaciones muy generales sobre el campo literario y su evolución a partir de casos particulares? Creo que sí: en este punto queda también la sensación de que la selección de los novelistas fue funcional a las hipótesis que la autora quería confirmar. Por lo demás, el libro contiene a ratos tantas aclaraciones seguidas de tantas generalidades que no puede uno dejar de preguntar si esta historia podría haber sido contada-con más acierto-de otra manera. Finalmente, considero que el enfoque de la teoría de los campos ha terminado por sobrepasar las observaciones críticas de la autora y se ha impuesto de manera excesiva en el libro: no sólo en su lenguaje, sino en las interpretaciones que ofrece. Es posible que tal enfoque homogéneo, regular y coherente, y de «dicotomías absolutas», haya extraviado un poco el propósito de captar las «características particulares» de nuestra historia literaria. 